\title{
Knowledge on self-management and levels of asthma control among adult patients in Ho Chi Minh City,Vietnam
}

This article was published in the following Dove Press journal: International Journal of General Medicine

\author{
Vinh Nhu Nguyen ${ }^{1-3}$ \\ Thuong Thi Hoai Huynh ${ }^{4}$ \\ Niels H Chavannes' \\ 'Department of Public Health \\ and Primary Care, Leiden \\ University Medical Center, Leiden, \\ the Netherlands; ${ }^{2}$ Department \\ of Family Medicine, Faculty of \\ Medicine, University of Medicine \\ and Pharmacy, Ho Chi Minh City, \\ Vietnam, ${ }^{3}$ Department of Respiratory \\ Functional Exploration, University \\ Medical Center, Ho Chi Minh City, \\ Vietnam, ${ }^{4}$ Faculty of Public Health, \\ University of Medicine and Pharmacy, \\ Ho Chi Minh City, Vietnam
}

Background: Most asthma patients in Vietnam have poorly controlled asthma. Besides reasons related to the health care system and health care providers, knowledge on the self-management of patients has also contributed to this situation.

Purpose: To assess knowledge on asthma self-management among adult asthma patients in Ho Chi Minh City.

Patients and methods: A cross-sectional study with convenience sampling was conducted among 322 ambulatory patients using questionnaires filled in via a face-to-face interview. The questionnaires enquired about: 1) sociodemographic details, 2) the Global Initiative for Asthma 2017 criteria of asthma control, 3) the Asthma Control Test, and 4) the Asthma Self-Management Questionnaire (ASMQ). Knowledge on asthma self-management was determined by the ASMQ score. The relationship between this knowledge and demographic factors and asthma control levels was determined.

Results: The knowledge on asthma self-management was low, with a mean raw ASMQ score of 4.3 (maximum 14); this is equivalent to 30 in a transformed score (maximum 100). Only $0.3 \%$ of these patients had good knowledge, $16.2 \%$ had adequate knowledge, and $83.5 \%$ had poor knowledge. Of all participants, $52 \%$ stated erroneously that asthma can be cured, $30 \%$ were confused about control and rescue medications, $68 \%$ failed to correctly describe the inhalation technique, and only $15.5 \%$ could answer correctly about the management of an exacerbation. Although most participants had poor asthma control, the higher the patient's level of control, the better the ASMQ score. Conversely, patients with better knowledge of asthma self-management (ASMQ score $\geq 50$ ) had better asthma control based on the Asthma Control Test score. Also, a higher education level was associated with more knowledge on asthma self-management.

Conclusion: In these patients, the level of knowledge on asthma self-management was low and significantly correlated with the level of asthma control. There is a clear need to improve knowledge in order to improve asthma control in Vietnam.

Keywords: asthma control, asthma knowledge, Asthma Self-Management Questionnaire, asthma patients

\section{Introduction}

Asthma is a major chronic disease among children and adults and remains a significant health problem in Vietnam. ${ }^{1-3}$ The prevalence of asthma in Vietnam among adults aged 21-70 years has been estimated at 3.9\%-5.6\%. ${ }^{4}$ In Ho Chi Minh city (where this study was conducted), the prevalence of "ever asthma" among 6-7 year olds was $10.9 \%$ and that of wheezing in children aged $13-14$ years was $29.5 \%$, the highest in the Asian-Pacific region. ${ }^{5}$
Correspondence: Vinh Nhu Nguyen University of Medicine and Pharmacy, 217 Hong Bang Street, District 5, Ho Chi Minh City 70000, Vietnam Email vinhnguyenmd@ump.edu.vn 
As asthma is a controllable disease, the aim of asthma management is to control the disease and allow patients to lead a normal and healthy life. ${ }^{6}$ To achieve this, patients need to use medications correctly and maintain control for a considerable period of time. This might be achieved if patients receive adequate guidance on how to use medications and receive sufficient knowledge about the disease. ${ }^{7}$ Patients should also be aware that adhering to the treatment plan is the mainstay of asthma management. ${ }^{7}$ In addition, asthma is a variable disease (i.e., it can change over time), implying that even when a patient has achieved a well-controlled asthma level, an asthma exacerbation can still occur. Therefore, patients need to know how to manage their disease and/or how to get help from health care providers when faced with an asthma exacerbation. ${ }^{8}$

Nowadays, despite many advances in asthma diagnosis and treatment, the prevalence of controlled asthma is still low worldwide, including in Vietnam. It is reported that the level of asthma control is still less than expected, that is, in Vietnam, $\leq 1 \%$ of patients have controlled asthma. ${ }^{9}$ Many reasons exist for this low level of asthma control, for example, related to the health care system and/or the doctor-patient relationship. Besides issues related to the health care system (e.g., unavailability of controllers, ${ }^{10}$ unaffordability for some patients ${ }^{1,2,1-13}$ ) or to physicians (e.g., incorrect diagnosis, lack of knowledge on asthma management, insufficient time or unwillingness to discuss matters with patients) $)^{14,15}$ and patient-related problems (e.g., low level of treatment adherence), the patient's low level of knowledge about the disease (particularly knowledge on self-management) is an important factor contributing to the low level of asthma control. ${ }^{16}$

Patients' general knowledge of asthma may comprise knowledge on the pathophysiology of asthma, the purpose of the different types of medication, the management of environmental asthma triggers, the identification/management of asthma exacerbations, the use of inhalers, and discrimination between controlled and uncontrolled asthma. ${ }^{17,18}$ However, general knowledge about asthma is not the same as knowledge about self-management. Self-management is based on the concept of self-efficacy, that is, an individual's belief or confidence in their ability to make decisions and engage in behaviors that successfully manage their chronic condition. Asthma self-management refers to what patients do to monitor/control their symptoms and to prevent exacerbations; these factors should be addressed in patient education. ${ }^{19}$

In many countries, although levels of asthma selfmanagement are low (regarding both knowledge and practice of asthma patients), these can be improved by means of education, ${ }^{20-23}$ and supported asthma self-management can lead to improved asthma control, fewer exacerbations/ hospital admissions, and improved quality of life. ${ }^{6,24,25}$

Currently, data are lacking regarding knowledge on the self-management of asthma in adult patients in Vietnam. Therefore, this study aimed to determine the level of asthma self-management knowledge, as well as the relationship between this knowledge and patients' level of asthma control and other demographic characteristics.

\section{Patients and methods}

\section{Study design and setting}

This was a prospective cross-sectional study. Eligible participants were ambulatory patients (recruited between May and July 2017) at the Asthma and COPD clinic, University Medical Center, Ho Chi Minh City, Vietnam.

\section{Ethical approval}

The study protocol was approved by the Institutional Review Board of the University of Medicine and Pharmacy at Ho Chi Minh City, Vietnam. All patients provided written informed consent to participate in this research.

\section{Inclusion and exclusion criteria}

Patients eligible for inclusion in this study were aged $\geq 18$ years, diagnosed at least 6 months before with asthma according to the Global Initiative for Asthma (GINA 2017), were followed up at this clinic, and had sufficient command of the Vietnamese language to respond to questionnaires.

Excluded were patients meeting any of the following exclusion criteria: 1) major medical morbidity; 2) cognitive impairment and unable to communicate verbally; 3) with asthma-COPD overlap syndrome; 4) refused to participate in the study; or 5) had an illness with symptoms similar to asthma.

\section{Sample size and sampling technique}

Based on the literature, it was assumed that the variance of the mean Asthma Self-Management Questionnaire (ASMQ) score, that is, $\sigma=1.6,{ }^{26}$ with maximum error deemed acceptable, that is, $\mathrm{d}=0.175$, error type $\mathrm{I} \alpha=0.05$, and normal variable, that is, $\mathrm{z}=1.96$ (95\% reliability of the estimates), the sample size required was 322 patients based on the formula $n=Z^{2}(1-\alpha / 2) \times \sigma^{2} / d^{2}$. A convenience method of sampling was adopted.

\section{Data collection}

Data were collected via a face-to-face interview using a structured questionnaire. The questionnaire had the following sections: 
1. Sociodemographics: This included information on gender, age, educational level, occupation, and duration of the disease.

2. GINA-2017 criteria of asthma control: These criteria have four items asking patients about daytime and nighttime symptoms of asthma, activity limitation, and use of rescue medication. This category can divide patients into the levels of asthma control: uncontrolled, partly controlled, and controlled asthma. ${ }^{6}$

3. Asthma Control Test (ACT): This test comprises five questions assessing the frequency of shortness of breath, frequency of asthma nighttime symptoms, degree of functional limitation, frequency of using rescuers, and patient's self-assessment of their level of asthma control. Each item has five response choices (each with a score ranging from 1 to 5). Accordingly, the level of asthma control is as follows: controlled (score 20-25), partially controlled (score 15-19), and uncontrolled (score <15). ${ }^{27}$ The Vietnamese version of this questionnaire has been validated ${ }^{28}$ and was used for this study.

4. ASMQ: The ASMQ is a validated tool used to assess patients' level of knowledge on self-care management. It comprises 16 multiple choice questions which measure knowledge of preventive strategies, correct inhaler use, medications (rescue and controller), and use of peak flow meters; it requires about 5 min to complete when self-administered or 8-10 min when interviewed. ${ }^{29}$ However, because peak flow meters are not in common use in Vietnam, for this study, the two items related to use of this device were removed. The scores for the tool were calculated as follows: 1) one point was assigned to each preferred response; 2 ) all the points were summed to generate the raw score range $0-14$; and 3 ) the raw score was transformed to range from 0 to 100 , with higher scores indicating more knowledge of asthma self-management. As in previous studies, ${ }^{30-32}$ the knowledge was categorized into the following levels: good (transformed ASMQ $>75$ ), adequate (transformed ASMQ 50-75), and poor (transformed ASMQ <50). The ASMQ was translated according to the World Health Organization process of translation and adaptation of instruments. ${ }^{33}$ This process involved the following steps: forward translation, expert panel back-translation, pretesting and cognitive interviewing, and the final version. ${ }^{33}$ A pilot study was conducted to test the questionnaire with a group of 20 patients to verify the feasibility and acceptability of the questionnaire and to establish the time frame for data collection. Minor alterations were suggested and adopted in the final version. The pilot sample was not included in the final analysis.

\section{Data analysis}

Data were processed with Epidata software and analyzed using STATA 12.0 software (copyright from the Public Health Department, University of Medicine and Pharmacy, Ho Chi Minh City, Vietnam). Ratio variables are presented as means and SD for a normal distribution variable (ASMQ) and median (quartile) for a non-normal distribution variable (ACT). Student's $t$-test was used to compare the means of two groups and one-way analysis of variance to compare the means of multiple groups. A $p$ value $\leq 0.05$ was considered statistically significant.

\section{Results \\ Characteristics of study patients}

Of the 350 patients invited to participate, 322 (92\%) with a mean age of 47 (range 18-91) years agreed. Males comprised $34 \%$ of the participants with a mean ACT score of 17 (95\% CI 13-21); additional characteristics are presented in Table 1. Data on the responses to the questionnaires are presented in Table 2.

Figure 1 shows that the question with the highest percentage of correct answers (59.3\%) is item 7 (After you have used your inhaler, you should hold your breath for several seconds) and that with the lowest percentage of correct answers (8.4\%) is item 9 (Taking more rescue medicines than prescribed may mean you need more maintenance medicine?). Item 9 was also the question that most often received the answer "Don't know/unknown" (i.e., 64.4\%). Figure 2 shows the distribution of the ASMQ transformed score.

The most frequently occurring incorrect response was to the question item 6 (When using your inhaler, you should inhale quickly), that is, by $64 \%$ of the responders.

\section{Discussion}

The main findings of this study are that knowledge of asthma self-management among adult asthma patients in Vietnam is low (mean raw ASMQ score of 4.3 [4.3/14] equal to 30 in transformed score [30/100]). Only $0.3 \%$ of adults had good knowledge, $16.2 \%$ had adequate knowledge, and $83.5 \%$ had poor knowledge. This result is comparable to previous reports. For example, Elbur et $\mathrm{al}^{26}$ reported that the mean raw score of ASMQ in their study (conducted in Saudi Arabia) with the same study format as ours (they also removed two items related to peak flow meter) was $3.5 / 14$. These authors found that only $4 \%$ of participants had $>50 \%$ correct 
Table I Characteristics of the study population $(\mathrm{N}=322)$

\begin{tabular}{|c|c|c|}
\hline Characteristics & Subgroups & Values \\
\hline Age (years) ${ }^{a}$ & & $\begin{array}{l}46.8 \pm 16.5 \\
(18-91)\end{array}$ \\
\hline \multirow[t]{3}{*}{ Age group ${ }^{b}$} & $18-35$ & $95(29.5)$ \\
\hline & $36-60$ & $160(49.7)$ \\
\hline & $>60$ & $67(20.8)$ \\
\hline \multirow[t]{2}{*}{ Gender $^{b}$} & Male & $109(33.8)$ \\
\hline & Female & $213(66.2)$ \\
\hline \multirow[t]{5}{*}{ Occupation $^{\mathrm{b}}$} & Officers & $32(9.9)$ \\
\hline & Housewives & $62(19.3)$ \\
\hline & Small business persons & $70(21.7)$ \\
\hline & Farmers & $39(12.1)$ \\
\hline & $\begin{array}{l}\text { Others (retired, teachers, } \\
\text { workers, and so on) }\end{array}$ & $119(37.0)$ \\
\hline \multirow[t]{4}{*}{ Level of education ${ }^{\mathrm{b}}$} & Primary school & $87(27.0)$ \\
\hline & Secondary school & $74(23.0)$ \\
\hline & High school & $78(24.2)$ \\
\hline & College or higher & $83(25.8)$ \\
\hline \multirow[t]{2}{*}{ Duration of asthma ${ }^{b}$} & $\leq 2$ years & $98(30.4)$ \\
\hline & $>2$ years & $224(69.6)$ \\
\hline $\mathrm{ACT}^{\mathrm{a}}$ & & $17(|3-2|)$ \\
\hline Level of asthma control & Controlled ${ }^{b}$ & $130(40.4)$ \\
\hline \multirow[t]{2}{*}{ based on ACT } & Partly controlled ${ }^{b}$ & $85(26.4)$ \\
\hline & Uncontrolled $^{\mathrm{b}}$ & $107(33.2)$ \\
\hline Level of asthma control & Controlled $^{\mathrm{b}}$ & $88(27.3)$ \\
\hline \multirow[t]{2}{*}{ based on GINA } & Partly controlled & $86(26.7)$ \\
\hline & Uncontrolled $^{\mathrm{b}}$ & $148(46.0)$ \\
\hline \multirow[t]{2}{*}{$\mathrm{ASMQ}^{\mathrm{a}}$} & Raw score ${ }^{a}$ & $4.3 \pm 2.1$ \\
\hline & Transformed score ${ }^{a}$ & $30.3 \pm 14.7$ \\
\hline Knowledge on asthma & Good $(>75)^{\mathrm{b}}$ & I $(0.3)$ \\
\hline \multirow[t]{2}{*}{ self-management } & Adequate $(50-75)^{\mathrm{b}}$ & $52(16.2)$ \\
\hline & Poor $(<50)^{\mathrm{b}}$ & $269(83.5)$ \\
\hline
\end{tabular}

Notes: aMean \pm SD (range); brequency (number and percentage).

Abbreviations: ACT, Asthma Control Test; ASMQ, Asthma Self-Management Questionnaire; GINA, Global Initiative for Asthma.

answers ${ }^{26}$ whereas it was $16.5 \%$ of participants in this study. In an intervention study using ASMQ as an indicator, Hiral et $\mathrm{a}^{34}$ reported a baseline mean ASMQ score of $4.49 / 16$ or 28.6/100 (using the full original version of ASMQ with 16 items) in the intervention group and $3.91 / 16$ or $24.4 / 100$ in the control group; there was a significant improvement in the intervention group compared with controls after an educational intervention. These mean scores are similar to ours (30/100), but are very low compared to those reported in two studies (conducted in the USA) by Mancuso et al (60/100)..$^{29,35}$

Many questionnaires are available to gain data on knowledge of asthma, regarding both general management and self-management. In term of general knowledge, previous studies reported a very low level of asthma knowledge among study samples. For example, Madhushani and Subasinghe found that only $34 \%$ of their patients in Sri Lanka had good knowledge on asthma and related medications. ${ }^{32}$ Sharifi et $\mathrm{a}^{31}$ observed that only $7.5 \%$ of Iranian asthma patients were knowledgeable about their disease, while this was $6 \%-10 \%$ among Indians. ${ }^{30,36} \mathrm{~A}$ multicenter study in China evaluating "Knowledge, Attitude, and Practices" of parents of children with asthma showed a low level of disease-related awareness, with poor understanding of the clinical manifestations of asthma and indicators of an acute attack. ${ }^{37}$ Similarly, insufficient knowledge levels were demonstrated by Merghani et al in Sudan ${ }^{38}$ and by Borges et al in Brazil. ${ }^{17}$

In Vietnam, many factors may contribute to the poor level of asthma knowledge. First, communication with the physician is the main source of education about asthma. Although there are other ways to get information in Vietnam (e.g., mass media, patients' clubs, education leaflets, and so on), these are very limited in some areas. This study was conducted in Ho Chi Minh City (the largest and most modern city of Vietnam), which offers the most advantages regarding patient education; however, many participants came from other provinces where they probably have less opportunities. In addition, in Vietnam, physicians working in a city hospital are often overloaded, implying that the time available for each patient is limited.

A second important item is the patient's education level. Many studies have demonstrated a relationship between asthma knowledge and patients' education, in which a higher education level was associated with more knowledge. 19,31,32,39-42 Some found that patients with a college education (or higher levels) had better asthma knowledge and asthma practice than those with less education. ${ }^{19,40}$ In this study, about $25 \%$ of the participants had a college education (or higher level) and these patients had a significantly higher ASMQ score compared to the other groups (Table 3 ). This is probably because patients with less education may not fully understand the information given by health care providers. Moreover, they may have a reduced capacity to integrate all the information provided to solve a particular problem. Also, in this study, an association was found between asthma self-management knowledge and occupation. However, this might also be related to education, as officers had the highest ASMQ scores and this group of participants also had the highest level of education.

Other demographic factors may also contribute to knowledge on asthma self-management, for example, gender, age, and duration of the disease. Earlier studies found that women had better knowledge about asthma than males, ${ }^{32,43}$ younger respondents had better scores than older respondents, ${ }^{19,32,41,43}$ and patients with a longer duration of asthma generally had better knowledge. ${ }^{31}$ However, even in these latter studies, not all of these factors occurred in any single study. ${ }^{31,32}$ Similarly, these relationships were not found in this study.

In our study, a relationship was found between ASMQ score and asthma control. The higher the level of control 
Table 2 Characteristics of incorrect responses to the ASMQ questions ( $N=322$ respondents)

\begin{tabular}{|c|c|c|}
\hline ASMQ items & Incorrect responses & n (\%) \\
\hline \multirow{3}{*}{$\begin{array}{l}\text { A main method to prevent asthma flare- } \\
\text { ups is to... }\end{array}$} & Take medicines before meals & $5 \mathrm{I}(15.8)$ \\
\hline & Take steroids in pill form & $55(17.1)$ \\
\hline & Go to the emergency room at the first sign of symptoms & $52(16.2)$ \\
\hline Taking the prescribed two puffs of your & Is the same as taking one puff four times a day & $24(7.5)$ \\
\hline \multirow[t]{2}{*}{ inhaler two times a day... } & Is the same as taking four puffs once a day & $3(0.9)$ \\
\hline & Can be arranged in any way as long as you take a total of four puffs a day & $4 \mathrm{I}(12.7)$ \\
\hline \multirow[t]{3}{*}{ If you are not having asthma symptoms... } & Your lungs are not sensitive to irritants & $23(7.1)$ \\
\hline & It is OK to skip some doses of medicine & $44(13.7)$ \\
\hline & You are probably cured of asthma & $20(6.2)$ \\
\hline \multirow[t]{3}{*}{ Maintenance medicines... } & Don't need to be taken every day & $4 \mathrm{I}(12.7)$ \\
\hline & Make you breathe better right after you take them & $117(36.3)$ \\
\hline & Can only be taken in pill form & $7(2.2)$ \\
\hline \multirow[t]{3}{*}{ Rescue medicines... } & Help prevent future flare-ups & $113(35.1)$ \\
\hline & Have no side effects & $21(6.5)$ \\
\hline & Do not cause you to become tolerant to medicine & $7(2.2)$ \\
\hline \multirow[t]{3}{*}{ When using your inhaler, you should... } & Take shallow breaths & $4(1.2)$ \\
\hline & Inhale quickly & $206(64)$ \\
\hline & Press your inhaler several times while you are inhaling & $9(2.8)$ \\
\hline After you have used your inhaler, you & Take the second puff as soon as possible after the first puff & $47(14.6)$ \\
\hline \multirow[t]{2}{*}{ should... } & Keep taking puffs until you feel better & $22(6.8)$ \\
\hline & Wash the inhaler in a tub of water & $9(2.8)$ \\
\hline If you are having symptoms and don't & Take some doses of steroid medicine & $120(37.3)$ \\
\hline know why, the first thing you should & Call your doctor & $68(21.1)$ \\
\hline do is... & Count how fast you are breathing & $8(2.5)$ \\
\hline Taking more rescue medicines than & Is really not harmful & $15(4.7)$ \\
\hline \multirow[t]{2}{*}{ prescribed... } & Is a good way to manage symptoms caused by exercise & $5 I(15.8)$ \\
\hline & May mean you can take less maintenance medicine & $21(6.5)$ \\
\hline \multirow[t]{3}{*}{ For people with asthma, exercise... } & Is something that should not be done regularly & $29(9.0)$ \\
\hline & Is only good if done for at least 30 minutes at a time & $67(20.8)$ \\
\hline & Can trigger symptoms because the lungs are not taking in enough oxygen & $62(19.3)$ \\
\hline \multirow[t]{3}{*}{ Asthma can be cured by... } & Taking daily medicine & $121(37.6)$ \\
\hline & Avoiding triggers, such as dust and cigarette smoke & $68(21.12)$ \\
\hline & Using a peak flow meter & I (0.3) \\
\hline \multirow[t]{3}{*}{ Asthma flare-ups... } & Usually occur suddenly without warning & $140(43.3)$ \\
\hline & Cannot be triggered by strong emotions & $13(4.0)$ \\
\hline & Always cause wheezing & $25(7.8)$ \\
\hline If you are prescribed a seven-day course & You don't have to avoid triggers while you are taking the pills & $14(4.4)$ \\
\hline \multirow[t]{2}{*}{ of steroid pills... } & Your symptoms can't get worse while you are taking the pills & $44(13.7)$ \\
\hline & You don't need to use your peak flow meter while you are taking the pills & $13(4.0)$ \\
\hline \multirow{3}{*}{$\begin{array}{l}\text { Which of the following can help control } \\
\text { asthma }\end{array}$} & Reducing stress levels & $58(18.0)$ \\
\hline & Drinking plenty of water to stay hydrated & $18(5.6)$ \\
\hline & Avoiding foods with sulfites, such as dried fruits and wine & $16(5.0)$ \\
\hline
\end{tabular}

Abbreviation: ASMQ, Asthma Self-Management Questionnaire.

(based on the ACT or GINA criteria), the better the ASMQ score (Table 4) and, conversely, patients with a better knowledge of asthma self-management (ASMQ score $\geq 50$ ) had better asthma control based on the ACT score (Table 5). This relationship between asthma knowledge and asthma outcomes was found in other studies, such as caregivers' knowledge and its relationship with asthma control among children in Saudi Arabia ${ }^{44}$ and in the USA. ${ }^{45}$ However, in elderly persons, no significant association was found between asthma control level and patients' asthma knowledge $(p=0.991) .{ }^{46}$ Earlier studies also reported that more general knowledge was associated with better scores on the Asthma Quality of Life Questionnaire in ambulatory and emergency department patients. ${ }^{47,48}$

In this study, we did not ask our patients about the use of a peak flow meter. Mancuso et al (the developers of this questionnaire) found that the ASMQ scores were higher in patients who owned a peak flow meter, although in their study (conducted in the USA), only $34 \%$ owned a peak flow meter. ${ }^{29} \mathrm{~A}$ similar result was reported by Abdulwadud et al in Australia. ${ }^{43}$ In most 


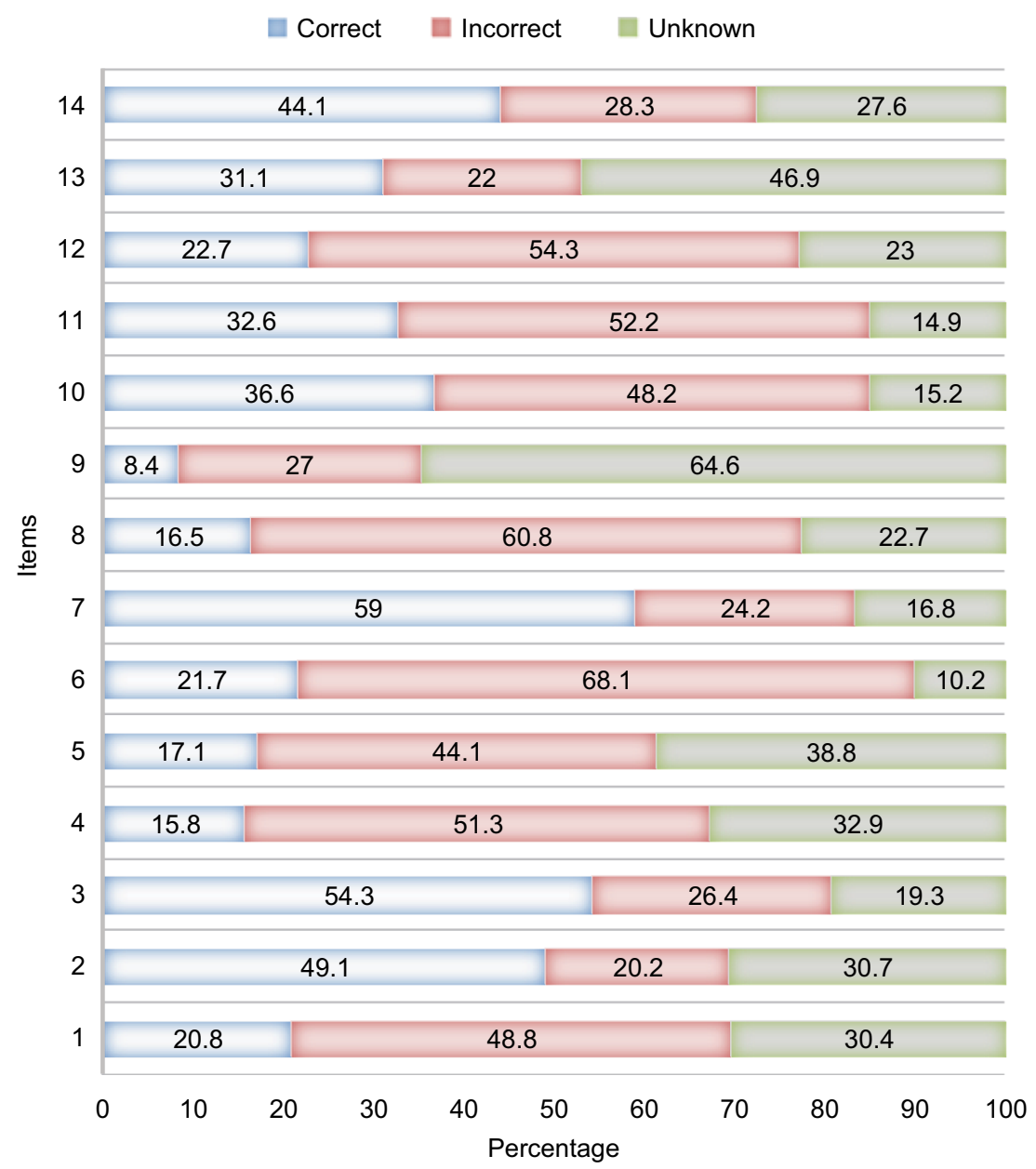

Figure I Response to the 14 items on the ASMQ ( $\mathrm{N}=322$ patients). Abbreviation: ASMQ, Asthma Self-Management Questionnaire.

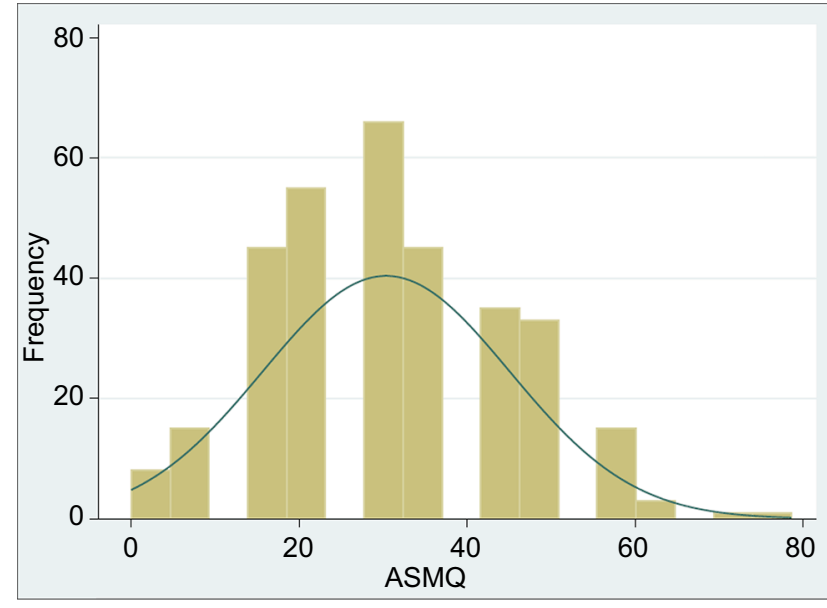

Figure 2 Distribution of the ASMQ transformed score: possible range 0-100, with higher scores indicating more knowledge of asthma self-management. Abbreviation: ASMQ, Asthma Self-Management Questionnaire.

developing countries, however, the use of this device is very low. For example, in a study in India, only $2 \%$ of patients were prescribed a peak flow meter by physicians. ${ }^{49}$
Table 3 Relationship between ASMQ and level of education, occupation, and duration of asthma disease

\begin{tabular}{|c|c|c|c|}
\hline \multicolumn{2}{|c|}{ Characteristics $(\mathrm{N}=322)$} & \multirow{2}{*}{$\begin{array}{l}\text { ASMQ score } \\
\text { Mean } \pm \text { SD } \\
31.2 \pm 15.3\end{array}$} & \multirow{2}{*}{$\begin{array}{l}p \text {-value } \\
0.346\end{array}$} \\
\hline Age group & $18-35$ & & \\
\hline \multirow[t]{2}{*}{ (years) } & $36-60$ & $30.8 \pm 14.7$ & \\
\hline & $>60$ & $28.0 \pm 13.9$ & \\
\hline \multirow[t]{2}{*}{ Gender } & Male & $29.5 \pm 14.5$ & 0.455 \\
\hline & Female & $30.8 \pm 14.8$ & \\
\hline \multirow[t]{5}{*}{ Occupation } & Officers & $38.2 \pm 16.9$ & $0.001 *$ \\
\hline & Housewives & $28.5 \pm 12.8$ & \\
\hline & Small business persons & $27.6 \pm 12.9$ & \\
\hline & Farmers & $26.2 \pm 15.0$ & \\
\hline & $\begin{array}{l}\text { Others (retired, teachers, } \\
\text { workers) }\end{array}$ & $32.2 \pm 15.0$ & \\
\hline \multirow{4}{*}{$\begin{array}{l}\text { Levels of } \\
\text { education }\end{array}$} & Primary school & $25.2 \pm 12.8$ & $<0.001 *$ \\
\hline & Secondary school & $30.2 \pm 13.2$ & \\
\hline & High school & $28.6 \pm 13.5$ & \\
\hline & College or higher & $37.5 \pm 16.3$ & \\
\hline \multirow{2}{*}{$\begin{array}{l}\text { Duration of } \\
\text { asthma }\end{array}$} & $\leq 2$ years & $32.4 \pm 13.4$ & 0.103 \\
\hline & $>2$ years & $29.5 \pm 15.2$ & \\
\hline
\end{tabular}

Note: *Statistically significant.

Abbreviation: ASMQ, Asthma Self-Management Questionnaire. 
Table 4 Relationship between ASMQ and levels of asthma control based on the ACT category and GINA criteria

\begin{tabular}{|c|c|c|c|c|c|}
\hline & & Controlled & Partly controlled & Uncontrolled & $p$-value \\
\hline \multirow[t]{2}{*}{ ACT } & $\mathrm{n}$ & 130 & 85 & 107 & $<0.001$ \\
\hline & ASMQ (Mean \pm SD) & $40.3 \pm 13.1$ & $28.2 \pm 11.6$ & $19.9 \pm 10.2$ & \\
\hline \multirow[t]{2}{*}{ GINA 2017} & $\mathrm{n}$ & 88 & 86 & 148 & $<0.001$ \\
\hline & ASMQ (Mean \pm SD) & $44.0 \pm 11.3$ & $32.1 \pm 13.0$ & $21.2 \pm 10.0$ & \\
\hline
\end{tabular}

Abbreviations: ACT, Asthma Control Test; ASMQ, Asthma Self-Management Questionnaire; GINA, Global Initiative for Asthma.

Table 5 Difference in ACT score between the groups: poor, adequate, and good knowledge of asthma self-management

\begin{tabular}{lll}
\hline $\begin{array}{l}\text { Asthma self-management } \\
\text { knowledge }\end{array}$ & $\begin{array}{l}\text { ACT score } \\
\text { (Mean } \pm \text { SD) }\end{array}$ & p-value \\
\hline Poor (ASMQ score $<50$ ) & $16.2 \pm 5.0$ & $<0.001$ \\
Adequate and good (ASMQ score $\geq 50)$ & $21.9 \pm 2.6$ & \\
\hline
\end{tabular}

Abbreviations: ACT, Asthma Control Test; ASMQ, Asthma Self-Management Questionnaire.

Regarding the use of a metered-dose inhaler, incorrect use of this device is often reported. ${ }^{50-53}$ In this study, although most patients $(59.3 \%)$ knew they should hold their breath for a few seconds after inhaling the medication into the lungs, $68 \%$ still gave a wrong answer about the use of an inhaler. In these incorrect responses, most patients (64\%) thought that to inhale quickly was the correct way to use an inhaler. Although this is wrong, it seems to persist as a common idea among both asthma and COPD patients worldwide. For example, it has been reported that nearly $60 \%$ of COPD patients ${ }^{54}$ and up to $90 \%-100 \%$ of asthma patients ${ }^{55-58}$ inhaled too quickly $\left(>90 \mathrm{~L} \mathrm{~min}^{-1}\right)$. Therefore, in practice, health care providers need to educate patients to inhale slowly when they prescribe a metered-dose inhaler.

Although it is confirmed that asthma is an incurable disease, this knowledge does not seem to have been transferred to all patients. In this study, $52 \%$ of the participants thought that asthma can be cured, mostly by medicine and by avoiding triggers. This finding is similar to the results of previous studies. For example, the belief that asthma can be cured was reported by $50.3 \%$ asthmatics in Pakistan, ${ }^{59} 40 \%$ in Saudi Arabia, ${ }^{60}$ and $32.1 \%$ of asthmatic school students in Oman. ${ }^{61}$ Similarly, using 14 items of the ASMQ, a study in Saudi Arabia found that only 25.5\% participants knew that there is no known cure for asthma. ${ }^{26}$

In addition, some confusion remains about rescue and control medications: for example, in this study, $36 \%$ of the participants thought that maintenance medicines can "make you breathe better right after you take them" and 35\% mentioned that rescue medicines can "help prevent future flareups". This type of confusion was also reported by Elbur et al: in their study (conducted in Saudi Arabia), only 22\% and
$16.6 \%$ of participants, respectively, had correct knowledge about controllers and rescuers. ${ }^{26}$

Regarding how to respond in a "bad" situation ("If you are having symptoms and don't know why, the first thing you should do is [...]?"), only $15.5 \%$ had a correct answer (i.e., to change one's immediate environment); this means that the active response to an acute exacerbation is far from optimal. On the other hand, many patients make serious errors in the management of an asthma attack. ${ }^{59,62,63}$

In general, this study has revealed a large gap in patients' asthma self-management knowledge, particularly among the less well-educated patients. This finding may hopefully lead to improvement/expansion of education programs for patients with asthma, which are still rare and of relatively poor quality in Vietnam.

It should be noted that, because this study was conducted in one hospital, the results may not be generalizable. In addition, no reliable causal relationships can be confirmed in this cross-sectional study. Furthermore, although the ASMQ was translated according to the World Health Organization procedure of translation and adaptation of instruments, the ASMQ has not yet been validated in Vietnam and this might have led to some bias.

\section{Conclusion}

This study shows that the knowledge of asthma selfmanagement of adult patients in Vietnam is low and that this knowledge is correlated with education level. A good relationship was found between asthma self-management and asthma control, that is, the higher the level of asthma control, the better the knowledge of asthma self-management (and vice versa). There is a need to improve knowledge of asthma self-management among adult patients in Vietnam, especially those who are less well educated, either via their physicians or by other appropriate means (e.g., via the mass media).

\section{Author contributions}

VNN and TTHH conducted the study. VNN and TTHH analyzed the data. VNN and TTHH drafted the manuscript. $\mathrm{NHC}$ edited the manuscript. All authors have reviewed the 
manuscript. All authors contributed toward data analysis, drafting and revising the paper, and all agree to be accountable for all aspects of the work.

\section{Disclosure}

The authors report no conflicts of interest in this work.

\section{References}

1. Nguyen TT, Nguyen NB. Economic burden of asthma in Vietnam: an analysis from patients' perspective. Value Health. 2014;17(7):A627.

2. Nguyen NB, Nguyen TT. Incidence-based cost of asthma in Vietnam. Value in Health. 2014;17(7):A777-A778.

3. Asthma in Vietnam. Statistics on Overall Impact and Specific Effect on Demographic Groups. Available from: http://global-disease-burden. healthgrove.com/1/48342/Asthma-in-Vietnam. Accessed September 5, 2017.

4. Lam HT, Ronmark E, Tu'o'ng NV, Ekerljung L, Chuc NT, Lundback B. Increase in asthma and a high prevalence of bronchitis: results from a population study among adults in urban and rural Vietnam. Respir Med. 2011;105(2):177-185.

5. Lai CK, Beasley R, Crane J, et al; Childhood Phase Three Study Group. Global variation in the prevalence and severity of asthma symptoms: phase three of the International Study of Asthma and Allergies in Childhood (ISAAC). Thorax. 2009;64(6):476-483.

6. Global Initiative for Asthma. Global strategy for asthma management and prevention. Available from: http://ginasthma.org/2017-gina-reportglobal-strategy-for-asthma-management-and-prevention/. Accessed August 01, 2017.

7. Tonnel AB, Schlatter J, Phương NHT. Control of asthma in 2010. J Fran Viet Pneu. 2010;01(01):19.

8. World Health Organization. asthma. 2013. Available from: http://www. who.int/mediacentre/factsheets/fs307/en/. Accessed December 20, 2017.

9. Lai CK, De Guia TS, Kim YY, et al; Asthma Insights and Reality in Asia-Pacific Steering Committee. Asthma control in the Asia-Pacific region: the Asthma Insights and Reality in Asia-Pacific Study. J Allergy Clin Immunol. 2003;111(2):263-268.

10. The International Union Against Tuberculosis and Lung Disease. The Global Asthma Report 2011. Paris, France: 2011. Available from: https://www.scribd.com/document/328173616/Global-AsthmaReport-2011. Accessed December 20, 2017.

11. Ait-Khaled N, Auregan G, Bencharif N, et al. Affordability of inhaled corticosteroids as a potential barrier to treatment of asthma in some developing countries. Int J Tuberc Lung Dis. 2000;4(3):268-271.

12. Nguyen AT, Knight R, Mant A, Cao QM, Martin A. Medicine prices, availability, and affordability in Vietnam. Southern Med Review. 2009;2(2):2-9.

13. Lai CKW, Kim YY, Kuo SH, Spencer M, Williams AE. Cost of asthma in the Asia-Pacific region. Eur Respir Rev. 2006;15(98):10-16.

14. Gonzalez Barcala FJ, de la Fuente-Cid R, Alvarez-Gil R, Tafalla M, Nuevo J, Caamano-Isorna F. [Factors associated with asthma control in primary care patients: the CHAS study]. Arch Bronconeumol. 2010;46(7):358-363. Spanish.

15. Haughney J, Price D, Kaplan A, et al. Achieving asthma control in practice: Understanding the reasons for poor control. Respir Med. 2008;102(12):1681-1693.

16. Nguyen K, Zahran H, Shahed, Peng J, Boulay E. Factors Associated with Asthma Control among Adults in Five New England States, 2006-2007. J Asthma. 2011;48(6):1-8.

17. Borges MC, Ferraz É, Pontes SM, et al. [Development and validation of an asthma knowledge questionnaire for use in Brazil]. J Bras Pneumol. 2010;36(1):8-13. Portuguese.

18. Schaffer SD, Yarandi HN. Measuring asthma self-management knowledge in adults. J Am Acad Nurse Pract. 2007;19(10):530-535.
19. Mancuso CA, Sayles W, Allegrante JP. Knowledge, attitude, and selfefficacy in Asthma self-management and quality of life. J Asthma. 2010;47(8):883-888.

20. Nair CC, Ajith B, Mathan S. Evaluation of the knowledge of patients, compliance to treatment and the impact of patient education on asthma: a questionnaire based study on outpatient asthmatics. Int Res J Pharm. 2014;5(5):444-448.

21. Prabhakaran L, Lim G, Abisheganaden J, Chee CB, Choo YM. Impact of an asthma education programme on patients' knowledge, inhaler technique and compliance to treatment. Singapore Med J. 2006; 47(3):225-231.

22. Manchana V, Mahal RK. Impact of asthma educational intervention on self-care management of bronchial asthma among adult asthmatics. Open J Nurs. 2014;4(11):743-753.

23. Varalakshmi M, Mahal RK. Evaluating asthma knowledge among patients with bronchial asthma; A Cross sectional study. Int $J$ Nurs Didactic. 2014;4(7):16-20.

24. Taylor SJC, Pinnock H, Epiphaniou E, et al. Health Services and Delivery Research. A Rapid Synthesis of the Evidence on Interventions Supporting Self-Management for People with Long-Term Conditions: PRISMS - Practical Systematic Review of Self-Management Support for Long-Term Conditions. Southampton (UK): NIHR Journals Library Copyright (c) Queen's Printer and Controller of HMSO; 2014.

25. British Thoracic Society/Scottish Intercollegiate Guideline Network. British guideline on the management of asthma: 2014 update. Thorax. 2014;69(Suppl 1):i1-i192.

26. Elbur A, Alharthi B, Alharthi S. Self-management and control of asthma among adult patients in King Faisal medical complex Taif, KSA. Int $J$ Res Pharm Sci. 2017;7(1):24-29.

27. Schatz M, Sorkness CA, Li JT, et al. Asthma Control Test: reliability, validity, and responsiveness in patients not previously followed by asthma specialists. J Allergy Clin Immunol. 2006;117(3):549-556.

28. Nguyen VN, Chavannes N, Le LT, Price D. The Asthma Control Test (ACT) as an alternative tool to Global Initiative for Asthma (GINA) guideline criteria for assessing asthma control in Vietnamese outpatients. Prim Care Respir J. 2012;21(1):85-89.

29. Mancuso CA, Sayles W, Allegrante JP. Development and testing of the Asthma Self-Management Questionnaire. Ann Allergy Asthma Immunol. 2009;102(4):294-302.

30. Malarvizhi M, Hariprasad B, Bhavani M. Determine the level of knowledge and practice among asthmatic patients attending chest opd at selected hospitals, Chennai. IJAICT. 2014;1(3).

31. Sharifi L, Pourpak Z, Heidarnazhad H, Bokaie S, Moin M. Asthma knowledge, attitude, and self-efficacy in Iranian asthmatic patients. Arch Iran Med. 2011;14(5):315-320.

32. Madhushani HPD, Subasinghe HWAS. Knowledge attitudes and practices of asthma; Does it associate with demographic factors of adult patients? Asian Pac J Health Sci. 2016;3(4S):94-99.

33. WHO. Process of translation and adaptation of instruments. Available from: http://www.who.int/substance_abuse/research_tools/translation/ en/. Accessed September 12, 2017.

34. Hiral P, ShobhaRani, Nalini P, Ramjan S, Sunitha C. Impact of patient education on quality of life of asthma patients in an IndianTertiary Care Hospital. Indian J Pharm Pract. 2013;6(4):50-55.

35. Mancuso CA, Wenderoth S, Choi TN, Westermann H, Wells MT, Charlson ME. Improvement in asthma quality of life in patients enrolled in a prospective study to increase lifestyle physical activity. J Asthma. 2013;50(1):103-107.

36. Kambli S. Asthma patient's knowledge regarding diagnosis and treatment. Int J Sci Res. 2014;3(6):1871-1876.

37. Zhao J, Shen K, Xiang L, et al. The knowledge, attitudes and practices of parents of children with asthma in 29 cities of China: a multi-center study. BMC Pediatr. 2013;13:20.

38. Merghani TH, Toum IM, Zaki AM, Ahmed AM. Knowledge, attitude and behaviour of asthmatic patients regarding asthma in urban areas in Khartoum State, Sudan. Khartoum Med J. 2011;4(1):524-531. 
39. Ho J, Bender BG, Gavin LA, O’Connor SL, Wamboldt MZ, Wambold FS. Relations among asthma knowledge, treatment adherence, and outcome. J Allergy Clin Immunol. 2003;111(3):498-502.

40. Scherer YK, Bruce S. Knowledge, attitudes, and self-efficacy and compliance with medical regimen, number of emergency department visits, and hospitalizations in adults with asthma. Heart Lung. 2001;30(4):250-257.

41. Meyer IH, Sternfels P, Fagan JK, Copeland L, Ford JG. Characteristics and correlates of asthma knowledge among emergency department users in Harlem. J Asthma. 2001;38(7):531-539.

42. Radeos MS, Leak LV, Lugo BP, Hanrahan JP, Clark S, Camargo CA, Jr. Risk factors for lack of asthma self-management knowledge among ED patients not on inhaled steroids. Am J Emerg Med. 2001;19(4):253-259.

43. Abdulwadud OA, Abramson MJ, Forbes AB, Walters EH. The relationships between patients' related variables in asthma: implications for asthma management. Respirology. 2001;6(2):105-112.

44. BinSaeed AA. Caregiver knowledge and its relationship to asthma control among children in Saudi Arabia. JAsthma. 2014;51(8):870-875

45. Wright Kelly J, Arnold Joshua, Culp Rachel, et al. "Asthma Knowledge, Control, and Administration Techniques in Hispanic Caregivers of Pediatrics” (2015). The Research and Scholarship Symposium. 6. Available from: http://digitalcommons.cedarville.edu/research_scholarship_symposium/2015/poster_presentations/6. Accessed December 20, 2017.

46. Ozturk AB, Ozyigit Pur L, Kostek O, Keskin H. Association between asthma self-management knowledge and asthma control in the elderly. Ann Allergy Asthma Immunol. 2015;114(6):480-484.

47. Leroyer C, Lebrun T, Proust A, et al. Knowledge, self-management, compliance and quality of life in asthma: a cross-sectional study of the French version of the Asthma Quality of Life Questionnaire. Qual Life Res. 1998;7(3):267-272.

48. Mancuso CA, Rincon M. Impact of health literacy on longitudinal asthma outcomes. J Gen Intern Med. 2006;21(8):813-817.

49. Kotwani A, Shendge S. Asthma Self-Management: A study in an emergency room of a chest hospital in Delhi, India. Southern Med Review. 2012;5(2):20-25.

50. Hesselink AE, Penninx BW, Wijnhoven HA, Kriegsman DM, van Eijk JT. Determinants of an incorrect inhalation technique in patients with asthma or COPD. Scand J Prim Health Care. 2001;19(4):255-260.
51. Nimmo CJ, Chen DN, Martinusen SM, Ustad TL, Ostrow DN. Assessment of patient acceptance and inhalation technique of a pressurized aerosol inhaler and two breath-actuated devices. Ann Pharmacother. 1993;27(7-8):922-927.

52. Broeders ME, Molema J, Hop WC, Folgering HT. Inhalation profiles in asthmatics and COPD patients: reproducibility and effect of instruction. J Aerosol Med. 2003;16(2):131-141.

53. Prasad R, Kushwaha RAS, Verma SK, et al. A study to know the knowledge, attitude, and practices of patients of bronchial asthma. Int J Med Public Health. 2013;3(3):159.

54. Al-Showair RA, Tarsin WY, Assi KH, Pearson SB, Chrystyn H. Can all patients with COPD use the correct inhalation flow with all inhalers and does training help? Respir Med. 2007;101(11):2395-2401.

55. Hardwell A, Barber V, Hargadon T, McKnight E, Holmes J, Levy ML. Technique training does not improve the ability of most patients to use pressurised metered-dose inhalers (pMDIs). Prim Care Respir J. 2011;20(1):92-96.

56. Plaza V, Sanchis J. Medical personnel and patient skill in the use of metered dose inhalers: a Multicentric Study. Respiration. 1998;65(3): 195-198.

57. Sanchis J, Gich I, Pedersen S. Systematic review of errors in inhaler use. Chest. 2016;150(2):394-406.

58. Al-Showair RA, Pearson SB, Chrystyn H. The potential of a 2Tone Trainer to help patients use their metered-dose inhalers. Chest. 2007;131(6):1776-1782.

59. Zaman M, Ashraf S, Javaid M. Reliability of diagnosis and asthma knowledge, attitudes and erception (KAP) in rural population of NWFP, Pakistan. Pak J Chest Med. 2006;12:17-22.

60. Donques AA, Alaki E, Almazyad W, Almutairi A. Knowledge and perception of asthmatic patients and their family towards asthma disease and management in King Saud Medical City, Riyadh, KSA. J Clin Respir Dis Care. 2017;3(1):128.

61. Anwar H, Hassan N, Jaffer N, Al-Sadri E. Asthma knowledge among asthmatic school students. Oman Med J. 2008;23(2):90-95.

62. Sibbald B. Patient self care in acute asthma. Thorax. 1989;44(2):97-101.

63. Jones KG, Bell J, Fehrenbach C, Pearce L, Grimley D, McCarthy TP. Understanding patient perceptions of asthma: results of the Asthma Control and Expectations (ACE) survey. Int J Clin Pract. 2002;56(2):89-93.
International Journal of General Medicine

\section{Publish your work in this journal}

The International Journal of General Medicine is an international, peer-reviewed open-access journal that focuses on general and internal medicine, pathogenesis, epidemiology, diagnosis, monitoring and treatment protocols. The journal is characterized by the rapid reporting of reviews, original research and clinical studies across all disease areas.

\section{Dovepress}

The manuscript management system is completely online and includes a very quick and fair peer-review system, which is all easy to use. Visit http://www.dovepress.com/testimonials.php to read real quotes from published authors. 